\title{
The Use of Learner Autonomy in English as a Foreign Language Context among Saudi Undergraduates Enrolled in Preparatory Year Deanship at Najran University
}

\author{
Ali Abbas Falah Alzubi (Corresponding author) \\ School of Languages, Literacies, and Translation, Universiti Sains Malaysia, PO box 11800, Penang, Malaysia \\ E-mail: aliyarmouk2004@gmail.com \\ Manjet Kaur Mehar Singh \\ School of Languages, Literacies, and Translation, Universiti Sains Malaysia, PO box 11800, Penang, Malaysia \\ E-mail: manjeet@usm.my \\ Ambigapathy Pandian \\ School of Languages, Literacies, and Translation, Universiti Sains Malaysia, PO box 11800, Penang, Malaysia \\ E-mail: ambiga@usm.my
}

Doi:10.7575/aiac.alls.v.8n.2p.152

URL: http://dx.doi.org/10.7575/aiac.alls.v.8n.2p.152
Received: 05/03/2017

Accepted: 17/04/2017

\begin{abstract}
This paper explores the current practices of learner autonomy among Saudi undergraduates at Preparatory Year, Najran University. The Short List questionnaire developed by Dixon (2011) was administered to measure the use of autonomous learning in English as a foreign language (EFL) context. Quantitative data were gathered from 208 male students in level one. The results of the data analysis showed that the participants experience a low level of learner autonomy (LA) in English language. While the LA dimensions of linguistic confidence, social comparison, and locus of control are considered a weakness for the participants, they had medium averages in information literacy, metacognition, and self-reliance dimensions. Therefore, the study suggests the need for pedagogical treatments like the strategy use instruction to develop LA in the Saudi EFL context.
\end{abstract}

Keywords: Autonomous Learning, Learner Autonomy, Preparatory Year, Saudi Arabia, Short List

\section{Introduction}

Learner autonomy (LA) has been seen as a revolutionary and resistant approach against the norm in education in general, and language teaching and learning in particular since 1980s. It is so as many current educational practices in public schools do more to implant dependency rather than to produce autonomous and lifelong learners taking control of their own learning (Al-Saadi, 2011; Grow, 1991). Consequently, the LA mode of education is extended to university and thus is imposing a lot of challenges; most importantly the inability to take any initiative for deciding what and how students will learn.

Undergraduates at Saudi universities are required to improve themselves as autonomous learners. They should be responsible, make decisions, and display self-confidence. They also need to develop critical thinking skills, as well as reasoning and problem-solving skills. However, Al-Saadi (2011) and Tamer (2013) state that the current educational system in Saudi Arabia features with the teacher's dominance and rote learning. As a result, this kind of education does not conform to the realities of today's world, and is therefore unsustainable as it does not provide creative learning activities engaging learners in autonomous learning.

The shift from the memorization methods of lecturing students to the novel idea of helping students teach themselves in today's world of language learning necessities that LA among EFL undergraduates is enhanced. LA goes beyond the rote memorization and direct lecturing. Autonomous learners are more respective of knowledge to involve active and conscious knowledge about learning (how things are processed) which will enable learners to exercise some control over the learning process and gradually achieve self-reliance (Al-Saadi, 2011; Sinclair, 1999). The need for LA stems from the argument that learners will be supposed to act on their own in English language learning, therefore, they will have to have a set of autonomous skills helping them to do so.

The rationale of autonomous language learning can be justified by a number of merits. Al-Saadi (2011) reports the most characteristics university graduates should have from the 2007 UK Higher Education Funding Council report, including the ability to apply knowledge when working with people, the need to be able to work independently, becoming efficient problem solvers, engagement in self-evaluation, and being able to develop higher order skills to become 
lifelong learners in an increasingly globalized, technological world. Little (1991) and Dickinson (1995) also emphasize that when learners are involved in decision making leads to more effective learning in which the barriers to learning that are often found in traditional teacher-led educational structures should not arise.

According to the researcher's knowledge, very little research has been conducted on exploring the LA current uses at the tertiary level in the Saudi EFL context. Therefore, it is of importance to identify the uses of LA as a baseline for further educational programs. Therefore, this study explores and measures the current autonomous learning practices among EFL undergraduates at Preparatory Year, Najran University, Saudi Arabia in order to suggest and work on pedagogical treatments in later stages.

\section{Review of Literature}

\subsection{Learner Autonomy}

LA in foreign language learning is an independently inclusive process in which learners are responsible for their learning, i.e. they choose materials, set goals, plan well, monitor their learning, and finally evaluate their progress (Benson \& Voller, 1997; Holec, 1981; Littlewood, 1996; Pruitt, 2005). According to Littlewood (1999), LA entails that learners are fully in charge of their learning because it can in any case only be carried out by the students themselves, and also they need to develop the ability to continue learning after the end of formal education. Learners are also to take ownership of many processes such as setting learning objectives, selecting materials, methods, and evaluating their progress.

Having pioneered this field, Holec's (1981: p.3) most cited definition of LA is 'the ability to take charge of one's own learning.' According to Holec, this ability is not inherited rather must be gained either by natural means or formal learning. The definition also entails a power or a capacity to act in learning. Holec (1981: p.3) manifests that learners should be responsible for all aspects of language learning: 'determining the objectives, defining the contents and progressions; selecting methods and techniques; monitoring the procedure of acquisition; evaluating what has been acquired.'

Holec sees that learning objectives are set according to the learner's analysis of the final behaviour aimed at. These objectives are subjected to change based on the learner's personal needs and motivations at any time. In connection, contents and progressions enable the objectives to be realized. Holec (1981: p. 12) defines contents as 'in terms of lexis, grammar, and phonology'. These contents are necessary for the oral and written learning of both comprehension and expression. Progressions 'are based on the degree of profitability of the elements incorporated and are judged by frequency and on the degree of complexity' (Holec, 1981: p.12). The learner chooses contents based on two propositions; the ideas he/she wants to understand and express in order to communicate and the words and grammar necessary to understand and express. That is to say the learner's first priority is communication, and to let this happen he/she thematically chooses contents helping him/her communicate. The learner can also decide the period needed to spread his/ her learning.

The third consecutive aspect is autonomous learning in which the learner is able to define methods and techniques available to him/her from previous experiences, other learners, and innovation. Based on the criteria of efficacy and adaptation to constraints of place, time and materials, the learner selects what methods he is convenient with (Holec, 1981, p.15).

Not very much different from progressions, in monitoring the acquisition procedure, the learner 'decides for himself herself when to study, how long to work at a time, and he $/$ she can therefore adjust his ther learning of acquisition rhythm' (Holec, 1981, p.16). The learner can decide when to speed up his her learning or increase the number of devoted hours. Finally, the process of evaluation includes judging what has been taken charge of in learning, from objectives and contents to selection of methods and techniques, monitoring learning and what has be gained (Holec, 1981, p.19).

To sum up, Holec's point is that the learner can have the ability to decide what, how, where, and when to learn. For him it is of no sense to passivize the learner and act for him her in setting goals, choosing materials and methods, monitoring and evaluating as he/she is knowledge recipient and best knows what best suits him

\subsection{Construct of Learner Autonomy}

Murase (2007) reviews the construct of LA in applied linguistics and classified it into four main categories: technical, psychological, political-philosophical and socio-cultural autonomy. According to her, technical autonomy found in Benson (1997)'s work is categorized into two sub-categories: behavioral (ability to learn on own' self through learning strategies) and situational (where learners are obliged to control their learning in physical settings and specific context and circumstances). Psychological autonomy which is considered as a prerequisite for technical autonomy refers to the learner's internal capacity (Little, 1991) that falls into three categories: motivation, metacognition and affection (Murase, 2007). The motivational aspect concentrates on the cognitive psychological approach to motivation that is closer to LA (Dickinson, 1995). Keller (cited in Crookes \& Schmidt, 1991) defines motivation as 'the choices people make as to what experiences or goals they will approach or avoid, and the degree of effort they will exert in that respect'. Ryan and Deci (2000) classify motivation into two areas: intrinsic (the free will of the reader in being interested to do an activity) and extrinsic (an external pressure to do an activity like a promise of a reward). Metacognition refers to metacognitive knowledge and reflection which can play a great role in enhancing LA through planning, monitoring, and evaluating (O'malley \& Chamot, 1990). The third category is affection. It involves factors 
such as anxiety, self-esteem and all the other emotions that may influence the process of language learning (Murase, 2007). Controlling these factors is necessary in order to develop LA.

Political-philosophical autonomy is concerned with the learner's perception of himself/herself about the world, and how it should be organized (Benson, 1997; Murase, 2007). This kind of autonomy is manifested into group and individual levels (Pennycook, 1997). Whilst group autonomy (positive freedom) is related to the group where the individual belongs to, and exercises some control over him/her, individual autonomy (negative freedom) refers to the one's control over all aspects of the learning process from the choice of materials to evaluation (Benson, 1997). The final type of autonomy is socio-cultural. This kind of autonomy is concerned with the learner's social interaction with others in developing LA(Vygotsky, 1980) and connotes learner's interdependence (Little, 1991). In this regard, learners seek to practice language, ask for help, and learn about culture (Oxford, 1990).

\subsection{Language Autonomous Learners}

According to Najeeb (2013), autonomous learners are able to reflect on their own learning through knowledge about learning, and who are willing to learn in collaboration with others. They understand the purpose of their learning program, share in the setting of learning goals, take initiatives in planning and executing learning activities, and regularly review their learning and evaluate its effectiveness.

In this regard, Nunan (2000) outlines common characteristics for people who successfully improved their language skills through learning autonomously. These characteristics and requirements include a diversity of skills, passion, and enjoyment for a particular field, a focused and active approach to learning, and finally, pursuit of learning and success despite high probability of failure and public disapproval. In other words, there is a consensus that the practice of LA requires insight, a positive attitude, a capacity for reflection, and a readiness to be proactive in self-management and interaction with others (Allwright, 1990; Holec, 1981; Little, 1991).

Having LA achieved in EFL context requires that certain conditions are obtained: learning strategies (cognitive and metacognitive), motivation and attitudes (perceptions), and knowledge about language learning or self-esteem (the evaluation that the learner makes of himself/herself about learning the target language) (Thanasoulas, 2000). Before this happens, three main components are to be established. First, learners should learn to be self-motivated and selfdisciplined in terms of course objectives, learning materials, activities, time and efforts spent. Second, Birchley (2003) sees that the roles of instructors in autonomous learning situations are resource person, language model, motivator, leader, facilitator, counselor and knowledge transmitter. Finally, learning environment is to give learners a sense of being in charge of their learning through practical lessons performed in-group work, communicative lessons in which it is easy to ask questions, and the lessons should be meaningful and interesting in the way that students are not forced to memorize by rote (Zarei \& Gahremani, 2010).

\subsection{Dixon's Model of Learner Autonomy}

Dixon (2011) explores the viability of using a quantitative instrument to measure autonomous learning and investigate whether such an instrument has a function in supporting teachers and learners in the development of LA in second language learning among 35 male and female Asian respondents enrolled at Warwick University. Dixon populated the questionnaire statements based on Oxford's (1990) Strategy Inventory for Language Learning, metacognition by Sinclair (1999), motivation questionnaires by Gardner and MacIntyre (1993) and Dornyeï (2001), and Cotterall (1995)'s learner beliefs questionnaire.

Dixon's scale covered the LA areas of control, skills, metacognition, strategies, confidence, motivation, social interaction, attitudes to learning, actions/ behaviours, and responsibility. These areas are classified into six categories which fall into two broad areas, technical (knowledge and skills), and psychological (including affect, which can block or promote the actualization of autonomy).

Under the technical umbrella, metacognition (reflection necessary to understand and internalize the knowledge about learning) and information literacy (how to go about learning) come. Dixon measured metacognition into three main areas: person, task, and strategy. Wenden (1998) describes learners' person knowledge as relating to knowledge and beliefs about, for example, aptitude or motivation and their ability as learners, both in general and for particular tasks. Task knowledge relates to knowledge of the purpose of a task, and how it will serve their language learning needs, the type or purpose of the task, and its demands. Strategic knowledge is awareness of strategies in general and when and how to use them (Wenden, 1998, pp. 518-519). Information literacy relates to the ability to retrieve information from online and printed sources. It deals directly with using sources to find information, using authentic texts, and an awareness of different types of text which is a useful skill to have for more effective interpretation of text (Dixon, 2011).

The psychological area is composed of linguistic confidence, social comparison, locus of control, and self-reliance. Linguistic confidence involves the idea of approaching a text from a building block or atomistic level (confidence about the ability with the language). It implies a feeling of insecurity or lack of confidence in approaching to a target language text. Social comparison involves learner's beliefs based on a relation or comparison to other people (i.e. confidence regarding relations with other people). Locus of control involves making one's own choices and taking responsibility for managing one's own learning. An internal locus, where the learner feels able to control, is preferable for autonomy to an external locus, where the learner feels less able to influence his $\backslash$ her own learning. Finally, self-reliance deals the ability to study independently, readiness to learn in unfamiliar ways, making choices, and decision-making. This area seems to be characterized by qualities related to the individual's sense of ability and self-reliance in learning (Dixon, 
Table 1. Dixon's model of learner autonomy

\begin{tabular}{|c|c|c|}
\hline Learner Autonomy & Dimensions & Areas \\
\hline Technical & $\begin{array}{ll}\text { Metacognition } & \text { and } \\
\text { information literacy } & \end{array}$ & $\begin{array}{ll}\text { control, skills, metacognition, } & \text { metivation, } \\
\text { strategies, confidence, motivat }\end{array}$ \\
\hline Psychological & $\begin{array}{l}\text { Linguistic confidence, } \\
\text { social comparison, locus } \\
\text { of control, self-reliance }\end{array}$ & $\begin{array}{l}\text { social interaction, attitudes to } \\
\text { learning, actions/behaviours, and } \\
\text { responsibility }\end{array}$ \\
\hline
\end{tabular}

Dixon's (2011) model may be helpful to examine the level of autonomous learning among preparatory year EFL male undergraduates as it is more inclusive and to some extent well-validated.

\subsection{Related Studies}

Chan, Spratt, and Humphreys (2002) investigate the conduct of LA in students' views of their responsibilities and decision-making abilities in learning English, their motivation level, and the actual language learning activities inside and outside the classroom. A questionnaire and a follow-up interview were applied to collect data among a group of tertiary students at the Hong Kong Polytechnic University. The study revealed that even when students had fairly positive attitudes to LA, they could be insufficiently motivated to take full control of their language learning. In addition, students' behaviour towards the outside and inside-class activities demonstrated little autonomy. Students did not seem to demonstrate what is usually seen as autonomous learning behaviour. Furthermore, it was showed that students did not appear to be ready for autonomous learning as they demonstrated a less positive attitude to accepting overall responsibility for their own learning although they felt able to make certain language-related decisions on their own. Unfortunately, this did not appear to translate into the expected autonomous language learning behaviour.

Üstünlüoğlu (2009) examines the perceptions of 320 Turkish university students and 24 teachers regarding responsibilities, abilities, and activities related to autonomous learning both inside and outside the classroom. A questionnaire and interview were used to gather data. The results suggested that students did not take responsibility for their learning although they have the ability, and teachers, themselves, take on most of the responsibilities. The results also suggested that ability and activity scores differ significantly according to gender, with females considering themselves more competent and more participatory than males in activities related to autonomous learning. Students surrender almost all responsibility to teachers, whereas they perceive themselves capable in several areas such as choosing learning activities and objectives inside/outside class, deciding how long to spend on each activity and evaluating learning.

Although there has been limited research on LA in Saudi Arabia, studies conducted do give some indications of students and teachers' perceptions on the effect of LA on teaching practices and outcomes in English language teaching (Farooq, 2013) and teachers' perceptions regarding the practices and prospects of LA in their classrooms (Al Asmari, 2013). Tamer's (2013) study on the readiness of the Saudi university male students on a preparatory English program to partake in autonomous learning of English as a foreign language (EFL) in terms of responsibilities, abilities, motivation, and English language activities indicated adequate levels of motivation and ability to take charge of their own learning. On the other hand, the participants lacked the sense of being responsible for cognitive and metacognitive learning aspects in learning English inside and outside the classroom.

The above review of literature indicates that LA areas of responsibilities, abilities, motivation, and activities have been broadly examined in various EFL contexts. However, other areas suggested by Dixon (2011) still need more investigation, especially in the Saudi context as very little research has been conducted on the actual use of LA in such context.

This study investigated the current practices of LA in foreign language acquisition among preparatory year undergraduate male students at Najran University to learn English language. Students in Preparatory Year are required to be more responsible and make decisions about their learning. They also need to carry out tasks and assignments on their own. Therefore, it is necessary that they are independent to succeed in their learning. This study is motivated by the notion that Preparatory Year students come from high school where rote memorization is deeply established and learners are fully dependent on the teacher (Tamer, 2013). In order to get more insights of the current use of LA at the university level, it is necessary that the exact level of LA be measured for further actions. Therefore, the study attempted to answer the question 'To what extent are undergraduates in Preparatory Year at Najran University EFL autonomous learners?'

\section{Methods}

In this exploratory study, the current practices of LA among English language learners were investigated. The quantitative design was employed to collect data about the six LA dimensions reported in the Short List by Dixon (2011). The validity and reliability of the instrument have been ensured. 
A total of 208 out of 450 randomly selected undergraduate students enrolled in Preparatory Year program (foundation year) participated in this study in the second semester 2016/2017. All the students involved share a number of characteristics. They are Saudi, male, ranging in age from 18 to 20, native speakers of Arabic, and study English as a foreign language (EFL). As part of their formal education, all of them have studied English for 8 years at school before university. The students in the scientific track at high school join the preparatory year at least for two semesters and compete for the medical, engineering, computer science, and administrative science faculties. The participants are in level one and study writing, reading, grammar, listening, speaking, computer, mathematics, and communicative skills.

\subsection{Questionnaire}

To answer the question of the study, a closed-statement questionnaire developed by Dixon (2011) was used in this study and referred as Short List scale. Through having surveyed literature, Dixon attempted to build a valid quantitative instrument able to measure autonomous learning. He identified the 10 areas of LA including control, skills, metacognition, strategies, confidence, motivation, social interaction, attitudes to learning, actions/behaviours, and responsibility. The 10 areas were classified into six categories: linguistic confidence, information literacy, social comparison, locus of control, metacognition, and self-reliance on the short list scale after running out factor analysis.

The six categories included 38 statements. Below each statement is the corresponding Arabic translation to ensure that respondents can fully understand it. The Short List translation was checked using the technique of back translation (Harkness \& Schoua-Glusberg, 1998). In the first stage, a translator was asked to translate the questionnaire into Arabic. Then, another translator was asked to back translate the Arabic into English. Finally, the original English version and the back translation of statements were compared to avoid any confusion that may result from language.

The Short List is aimed at identifying the respondents' current level of LA. It is composed of 38 statements rated on a five-point Likert scale ( $1=$ strongly disagree, $2=$ disagree, $3=$ neither agree nor disagree, $4=$ agree, $5=$ strongly agree). In order to avoid biasness and keep conscious when filling out the questionnaire, the categories are not provided in the questionnaire, and the statements are randomly enlisted as shown in Table 2 below.

Table 2. The distribution of statements on categories

\begin{tabular}{ll}
\hline Categories & Statements \\
\hline Psychological confidence & $1,5,11,15$, and 22 \\
\hline Information literacy & $2,9,13,19,24,28,32$, and 35 \\
\hline Social comparison & 3,8, and 26 \\
\hline Locus of control & $10,18,23,29$, and 34 \\
\hline Metacognition & $4,7,12,16,20,25,30,33,36$, and 38 \\
\hline Self-reliance & $6,14,17,21,27,31$, and 37 \\
\hline
\end{tabular}

The questionnaire includes information about the study purpose in general, confidentiality, and the use of data for scientific purposes (Dörnyei, 2003).

\subsection{Data collection and Analysis}

Upon acceptance to use the Short List by Dixon (2011), the questionnaire copies were distributed to randomly selected students in level one English classes with the help of teachers in their respective sections.

Data gathered were analyzed using descriptive statistics. The Statistical Package for the Social Sciences (SPSS) was employed to analyze the survey data. The survey results on the Short Scale were scored and analyzed using a 5-point Likert Scale, Weighted Mean, Standard Deviation, and Ranking.

Table 3 which shows the Cronbach's alpha of the factor groupings. It should be above .7 and not below .6 (Dörnyei, 2007, p. 207). The Short list was piloted in the context of the study on 30 participants other than those who participated in the study. It can be seen that the overall internal reliability is .81 which can be considered as a good degree. However, factors such as linguistic confidence (.68), social comparison (.61), and locus of control (.69) scored below.70 due to the less number of statements under those subscales. The internal reliability of the factors is close to the internal reliability (above .70) of the Short List by Dixon (2011).

Table 3. Internal Reliability of the Scale

\begin{tabular}{llll}
\hline $\mathrm{N}$ & Categories & $\begin{array}{l}\text { No. of } \\
\text { statements }\end{array}$ & Reliability - Cronbach's Alpha \\
\hline 1 & Linguistic confidence & 5 & 0.68 \\
\hline 2 & Information literacy & 8 & 0.76 \\
\hline 3 & Social comparison & 3 & 0.61 \\
\hline 4 & Locus of control & 5 & 0.69 \\
\hline 5 & Metacognition & 10 & 0.78 \\
\hline 6 & Self-reliance & 7 & 0.75 \\
\hline 7 & Total & 38 & 0.81 \\
\hline
\end{tabular}




\section{Results}

In this study, the Short List was administered to statistically describe the level of participants' LA as shown in Table 2 below. Table 4 displays that the participants' overall level of LA is (2.49) on a five-point scale. The scale averages are calculated as follows:

(1-1.80=very low;1.81-2.60=low; 2.61-3.40=medium; 3.41-4.20=high;4.21-5=very high)

The questionnaire measured the six factors of LA: linguistic confidence (1.64); information literacy (2.84); social comparison (2.84); locus of control (1.86); metacognition (2.75); and self-reliance (2.97) with an overall mean of (2.49). That is to say that the overall level of participants' LA is low (2.49).

Table 4. Short list descriptive statistics

\begin{tabular}{|c|c|c|c|c|}
\hline Factor-statements & $\mathrm{N}$ & $\begin{array}{l}\text { Mean } \\
\text { s }\end{array}$ & $\begin{array}{l}\text { Std. } \\
\text { Deviation }\end{array}$ & Level \\
\hline 1. Linguistic Confidence & & 1.64 & .43 & Very low \\
\hline 1. I don't worry if I don't understand all the grammar in a text. & 208 & 1.44 & .60 & Very low \\
\hline 5. I don't worry if I don't understand all the words in a text. & 208 & 1.79 & .89 & Very low \\
\hline 11. I don't worry if I don`t understand everything when I listen. & 208 & 1.56 & .69 & Very low \\
\hline $\begin{array}{l}\text { 15. When I read an English text, I don't need to understand every word in } \\
\text { it. }\end{array}$ & 208 & 1.67 & .70 & Very low \\
\hline 22. Every word isn't important for understanding a listening text. & 208 & 1.73 & .81 & Very low \\
\hline Information Literacy & & 2.84 & .50 & Medium \\
\hline 2.I know the parts of a book (index, glossary, contents, chapters). & 208 & 2.90 & .99 & Medium \\
\hline 9.I know how to use English language reference books. & 208 & 2.40 & .95 & Low \\
\hline 13.I know how to find the information I need on the Internet. & 208 & 2.79 & 1.20 & Medium \\
\hline 19.I know how to find information in a library. & 208 & 2.63 & .98 & Medium \\
\hline 24.I use real English texts (i.e. not made for students) in my learning. & 208 & 2.31 & .87 & Low \\
\hline 28.I look at causes and effects logically. & 208 & 3.04 & .98 & Medium \\
\hline 32.I am confident I can learn English well. & 208 & 3.79 & 1.23 & High \\
\hline 35.I change the way I write according to who will read it. & 208 & 2.85 & 1.03 & Medium \\
\hline Social Comparison & & 2.03 & .51 & Low \\
\hline 3.The other students are not more confident than me at speaking English. & 208 & 1.98 & .70 & Low \\
\hline 8.The other students don't know English better than me. & 208 & 2.23 & .75 & Low \\
\hline $\begin{array}{l}\text { 26.I think learning English is more difficult for me than for the average } \\
\text { learner. }\end{array}$ & 208 & 1.88 & .75 & Low \\
\hline Locus of Control & & 1.86 & .49 & Low \\
\hline 10.My way of learning will change. & 208 & 2.00 & .86 & Low \\
\hline 18.To remember vocabulary you don't need to be talented. & 208 & 2.00 & .76 & Low \\
\hline 23.Memorizing answers isn't the best way to learn. & 208 & 1.87 & .94 & Low \\
\hline 29.I don't learn English because I have to. & 208 & 1.71 & .91 & Very low \\
\hline 34. To read you don't need to proceed word by word. & 208 & 1.71 & .82 & Very low \\
\hline Metacognition & & 2.75 & .35 & Medium \\
\hline 4.I am an active dynamic person. & 208 & 3.46 & 1.05 & High \\
\hline 7.It is my job to check my work for mistakes. & 208 & 3.12 & 1.05 & Medium \\
\hline 12.I talk to others about how I feel about learning English. & 208 & 3.08 & 1.11 & Medium \\
\hline 16.I know techniques to help me remember vocabulary. & 208 & 2.52 & .91 & Low \\
\hline 20.I predict the content before I listen. & 208 & 2.40 & .79 & Low \\
\hline 25.I have changed the way I learn after thinking about it. & 208 & 2.48 & .89 & Low \\
\hline 30.I can describe the learning strategies I use. & 208 & 2.27 & .76 & Low \\
\hline 33.I fix my problems in vocabulary. & 208 & 2.37 & .86 & Low \\
\hline 36. My writing is better now than it was a year ago. & 208 & 3.62 & 1.31 & High \\
\hline 38.I choose the exercises I work on. & 208 & 2.15 & .82 & Low \\
\hline Self-Reliance & & 2.97 & .45 & Medium \\
\hline 6.I can study independently. & 208 & 3.31 & 1.41 & Medium \\
\hline 14.I am good at making choices. & 208 & 2.50 & .95 & Low \\
\hline 17.I can choose the method of learning that suits me best. & 208 & 2.31 & 1.03 & Low \\
\hline 21.I am ready to learn in unfamiliar ways. & 208 & 3.10 & 1.41 & Medium \\
\hline 27.I notice how other people use English. & 208 & 3.27 & 1.02 & Medium \\
\hline 31.I organize my time for studying. & 208 & 3.52 & .99 & High \\
\hline 37.I am good at studying on my own. & 208 & 2.79 & 1.38 & Medium \\
\hline All categories & 208 & 2.49 & .27 & Low \\
\hline
\end{tabular}


Among the six different factors of the Short List, two main averages emerged: low and medium. While the low averages included linguistic confidence, locus of control, and social comparison, the medium averages had metacognition, information literacy, and self-reliance.

Linguistic confidence scored the lowest mean (1.64); very low and a standard deviation of .43 at each statement and the overall. The more linguistic confidence is high the more less worried and confident learners are. This factor is related to issues of worry regarding English skills such as grammar and listening, and word-by-word comprehension. While statements 1 and 11 scored the lowest means (1.44) and (1.56) with standard deviations of .60 and .69, the means of the statements 5 and 22 ranked the highest (1.79) and (1.73) with standard deviations of .89 and .81 respectively.

The second lowest factor, locus of control, scored a low mean of 1.84 and a standard deviation of .49. This factor is related to issues of empowering learners to control what they learn. The participants did not show a sense of control towards their ways of learning (2.00), memorizing answers (1.87), being talented to remember vocabulary (2.00), the purpose behind learning English (1.71), and learning word by word (1.71). In order for learners to be autonomous in learning, they need to change how they learn and be intrinsically motivated to learn the language.

Social comparison came third with a mean of 2.03 and a standard deviation of .51. This dimension is about learner's beliefs in comparison with other people. All the three statements scored low means of 1.98, 2.23, and 1.88 and standard deviations of $.70, .75$, and .75 in order.

Metacognition, information literacy, and self-reliance scored medium means $(2.75,2.84$, and 2.97$)$ in a row. Metacognition which has to do with issues related to the knowledge of person, task, and strategy was the lowest in the medium means (2.75) and a standard deviation of .35. The means and standard deviations of the statements in this factor varied: low, medium, and high. Statements 30 and 38 ranked last; (2.27) and (2.15), while statements 4 and 36 showed high responses; (3.46) and (3.62) in a row.

Information literacy is about the ability to retrieve information from online and printed sources which showed medium means (2.84) and a standard deviation of .50. Statements 9 (using English references books) and 24 (using real English texts) ranked last with means of 2.40 and 2.31 respectively. Statement 32 (being confident to learn English well) scored as high as (3.79). The rest of statements 2,13,19,28 and 35 were medium.

The last factor is self-reliance. This dimension is related to the individual's sense of ability and self-reliance in learning. It topped the medium dimension with a mean of 2.97and a standard deviation of .45. While statements 14 and 17 scored low means (2.50 and 2.31 in a row), statement 31 ranked high (a mean of 3.52). The other statements had medium scores.

\section{Discussion}

The study investigated the question 'To what extent are undergraduates in Preparatory Year at Najran University EFL autonomous learners?' Data obtained from the questionnaire analysis could be an indicator of strong and weak areas in learning settings to serve as a tool to develop autonomous learning (Dixon, 2011). Dixon elaborated that the data by the autonomy questionnaire should not be used as a measure of abstract autonomy, but as a source of data which are related to LA for use in a primarily comparative measurement for monitoring and facilitating autonomy in the classroom.

The results suggest that the overall level of autonomous learning among Preparatory Year male undergraduates is low (2.49). Linguistic confidence, social comparison, and locus of control are considered a weakness for the participants. Participants also had medium averages on information literacy, metacognition, and self-reliance. Table 5 displays the averages of LA dimensions in comparison with those by Dixon (2011) as they appear in the scale.

Table 5. Result comparison to Dixon (2011)

\begin{tabular}{lll}
\hline Dimension & Dixon $(2011) \%$ & This study $\%$ \\
\hline Linguistics Confidence & 57.72 & 32.8 \\
\hline Information Literacy & 74.19 & 56.8 \\
\hline Social Comparison & 56.77 & 40.6 \\
\hline Locus of Control & 57.72 & 37.2 \\
\hline Metacognition & 70.17 & 55 \\
\hline Self-Reliance & 72.73 & 59.4 \\
\hline
\end{tabular}

The results of this study are in line with those results by Tamer's (2013) study in which Saudi students showed low level of LA as they are still being taught in teacher-controlled classrooms where rote learning is the tradition. In addition, the results do agree with those results of the study by Üstünlüoğlu (2009) in which students did not take responsibility for their language learning. Likely, the overall mean of the LA in this study is parallel with that by Chan et al. (2002) who showed that students did not seem to demonstrate what is usually seen as autonomous learning behaviour and did not appear to be ready for autonomous learning as they demonstrated a less positive attitude to accepting overall responsibility for their own learning are in line with this study findings.

Students' LA uses range from low to medium while learners in Tamer's study expressed adequate levels of motivation and ability to take charge of their own learning. Students in this study experience low LA practices which contradicts with Üstünlüoğlu (2009) who showed that students perceived themselves capable in several areas such as choosing 
learning activities and objectives inside/outside class, deciding how long to spend on each activity and evaluating learning.

The low averages of autonomous learning in English language may be attributed to a number of reasons. Al-Saadi (2011) observes 'The previous schooling has regrettably failed to create curious and autonomous learners who are willing and see the need to take control of their own learning, or at least some aspects of their learning such as selfassessment and reflection'. (p. 100)

Tamer (2013) adds that the school inherited habits such as the teacher's dominance and rote memorization that can limit their free well to learn autonomously. The current education system in Saudi Arabia lags far behind all these autonomous developments in teaching English as a foreign language (EFL), in which learners are passive. Saudi students are still being taught in teacher-controlled classrooms where rote learning is the tradition. As a result, they turn into fossilized spoon feeders that depend on teachers for all their learning needs.

\section{Conclusion}

This study aimed at investigating the current practices of LA in EFL context. The Short List scale was administered to decide to what extent the Saudi undergraduates in Preparatory Year at Najran University are autonomous learners. The data analysis showed that the respondents are low autonomous learners. This overall low level urges the need for pedagogical treatments to develop LA dimensions so as to have a more improved and sustained learning.

LA in its abstract sense may be very difficult to measure quantitatively. However, the act of autonomous learning that is covered by a number of areas related to psychology and technicality can be measured. Therefore, in this study and others alike, LA dimensions are proved to be measured using the Short List by Dixon (2011). Teachers can use quantitative instruments like Short List to follow up their students' LA development, and learners themselves can have it as a self-assessment list to monitor their autonomous learning progress.

The study implicates that the role of school should exceed the issue of enabling learning to reach a worthwhile level of proficiency in the language to equip them with the attitudes and skills to continue to plan, carry out and monitor their own language learning as (Benson, 2010; Cotterall, 1995; Littlewood, 1996). Further research on the use of strategy instruction in language learning as one method to enhance LA is recommended.

\section{References}

Al-Saadi, H. M. (2011). From Spoon Feeding to Self-Feeding: Helping Learners Take Control of Their Own Learning. Arab World English Journal, 2(3), 95-114.

Al Asmari, A. (2013). Practices and prospects of learner autonomy: Teachers' perceptions. English Language Teaching, 6(3), 1 .

Allwright, D. (1990). Autonomy in language pedagogy. CRILE Working Paper, 6.

Benson, P. (1997). The philosophy and politics of learner autonomy. Autonomy and independence in language learning, 7, 18-34.

Benson, P. (2010). Measuring autonomy: Should we put our ability to the test. Testing the untestable in language education, 77-97.

Benson, P., \& Voller, P. A. (1997). Independence in Language Learning: London: Longman.

Chan, V., Spratt, M., \& Humphreys, G. (2002). Autonomous language learning: Hong Kong tertiary students' attitudes and behaviours. Evaluation \& Research in Education, 16(1), 1-18.

Cotterall, S. (1995). Readiness for autonomy: Investigating learner beliefs. System, 23(2), 195-205.

Dickinson, L. (1995). Autonomy and motivation a literature review. System, 23(2), 165-174.

Dixon, D. (2011). Measuring language learner autonomy in tertiary-level learners of English. University of Warwick.

Dornyeï, Z. (2001). Teaching and Researching Motivation, England: Pearson Education Limited. P111-25.

Dörnyei, Z. (2007). Research methods in applied linguistics: Quantitative, qualitative, and mixed methodologies: Oxford University Press.

Dörnyei, Z. (2003). Questionnaires in second language research: Constructing, administering, and processing: Mahwah, NJ: Lawrence Erlbaum Associates.

Farooq, M. U. (2013). Effects of learner autonomy on teaching practices and outcomes in an ELT classroom. Eur. J. Sci. Res, 94, 316-330.

Gardner, R. C., \& MacIntyre, P. D. (1993). On the measurement of affective variables in second language learning. Language Learning, 43(2), 157-194.

Grow, G. O. (1991). Teaching learners to be self-directed. Adult education quarterly, 41(3), 125-149.

Harkness, J. A., \& Schoua-Glusberg, A. (1998). Questionnaires in translation: DEU.

Holec, H. (1981). Foreign Language Learning: Oxford: Pergamon Press. 
Little, D. (1991). Autonomy: Definitions, issues and problems. Dublin: Authentik.

Littlewood, W. (1996). “Autonomy”: An anatomy and a framework. System, 24(4), 427-435.

Littlewood, W. (1999). Defining and developing autonomy in East Asian contexts. Applied linguistics, 20(1), 7194.

Murase, F. (2007). Operationalising the Construct of Learner Autonomy: A Preliminary Study for Developing a New Measure of Language Learner Autonomy. Paper presented at the proceedings of Independent Learning Association 2007 Japan Conference: Exploring Theory, Enhancing Practice, held in Kanda University of International Studies, Chiba, Japan.

Najeeb, S. S. (2013). Learner autonomy in language learning. Procedia-Social and Behavioral Sciences, 70, 12381242.

Nunan, D. (2000). Autonomy in language learning. Paper presented at the at the ASOCOPI 2000 conference, Cartengena, Columbia

O'malley, J. M., \& Chamot, A. U. (1990). Learning strategies in second language acquisition: Cambridge university press.

Oxford, R. (1990b). Language learning strategies. What every teacher should know? Boston: Heinleand Heinle. Pruitt, D. (2005). Transactional distance and learner autonomy as predictors of student performance in distance learning courses delivered by three modalities. Unpublished doctoral dissertation, Tulane University, USA.

Ryan, R. M., \& Deci, E. L. (2000). Intrinsic and extrinsic motivations: Classic definitions and new directions. Contemporary educational psychology, 25(1), 54-67.

Sinclair, B. (1999). More than an act of faith? Evaluating learner autonomy. Innovation and best practice in British ELT. London: Longman (in association with the British Council).

Thanasoulas, D. (2000). What is learner autonomy and how can it be fostered. The Internet TESL Journal, 6(11), $37-48$.

Üstünlüoğlu, E. (2009). Autonomy in language learning: Do student take responsibility for their learning. Journal of Theory and practice in Education, 5(2), 148-169.

Vygotsky, L. S. (1980). Mind in society: The development of higher psychological processes: Harvard University press.

Wenden, A. L. (1998). Metacognitive knowledge and language learning1. Applied linguistics, 19(4), 515-537.

Zarei, A., \& Gahremani, K. (2010). On the relationship between learner autonomy and reading comprehension: TELL. 